\title{
Nursing does affect the duration of the post-partum to ovulation interval in cotton-top tamarins (Saguinus oedipus)
}

\author{
T. E. Ziegler, T. M. Widowski, M. L. Larson and C. T. Snowdon \\ Department of Psychology, University of Wisconsin, 1202 West Johnson St, Madison, \\ Wisconsin 53706, USA
}

\begin{abstract}
Summary. Reports on callitrichid monkeys have not revealed a significant effect of nursing on interbirth intervals or on post-partum to ovulation intervals. We examined 25 post-partum intervals in cotton-top tamarin females to determine whether nursing infants would affect the length of the post-partum to ovulation interval. Urinary LH/ $\mathrm{CG}$ and oestrone conjugates were measured in urine samples collected in the 6 weeks after birth. The post-partum to ovulation interval is the number of days between parturition and the rise of urinary $\mathrm{LH}$ and oestrone conjugates associated with ovulation. There was an $84 \%$ conception rate post partum. Neither mother's parity nor sex of the infants influenced the length of the post-partum to ovulation interval. The post-partum to ovulation interval for females nursing 2 infants was twice as long as for those not nursing or nursing 1 infant $(P<0.05)$. The range of post-partum to ovulation interval lengths was more variable in nursing than in non-nursing females $(P<0.01)$. Females spent less than $50 \%$ of observed time in contact and less than $20 \%$ of observed time nursing their infants. Neither the number of tamarins within the family nor the amount of time the mother was in contact with infants correlated with the length of the postpartum to ovulation interval. However, there was a positive correlation between the percentage time that mothers nursed 1 infant at a time and the length of the postpartum to ovulation interval $(r=0.75, P<0.02)$. The underlying mechanisms of suckling-induced delay of ovulation are present in the cotton-top tamarin as in other primate species. However, these nursing effects do not cause the substantial delay in fertility post partum that is associated with non-callitrichid primates.
\end{abstract}

Keywords: lactational amenorrhoea; nursing behaviour; post-partum fertility; tamarins

\section{Introduction}

For most mammals, a reduction in fertility follows birth. The reduction in fertility is more pronounced in lactating females and is indicated by a longer interval between birth and the onset of ovarian cycling (post-partum to ovulation interval). Lactational effects on fertility are mediated through a neural stimulus received from the suckling stimulus. This neural stimulus suppresses gonadotrophin secretion (see McNeilly, 1988, for review). The nature of the suckling stimulus is determined by the behaviour of both the mother and the neonates and can be influenced by the frequency of nursing, the duration of the nursing bouts and the intensity of the suckling stimulus, i.e. multiple infants or variation in the strength of the infant's suck (Lunn, 1988; McNeilly, 1988; McNeilly et al., 1988).

Decreased fertility due to lactation or, more specifically, the suckling stimulus from infants has been reported for most primate species. Breast-feeding in humans is known to delay the postpartum ovulation and menses for as short as 2-3 months or as long as 3-4 years (McNeilly, 1988). 
In gorillas and chimpanzees, lactating females have 3-5-year interbirth intervals (Tutin, 1980; Short, 1983; Stewart, 1988). In Old World species, non-seasonal breeders such as the baboon have a lactation-induced amenorrhoea that may last an average of 420 days (Nicolson, 1981). For seasonal breeders, such as rhesus macaques, the combination of the lactational and seasonal effects can delay ovulations for 1-2 years. New World monkeys, such as the spider monkey (Wolf et al., 1975), the howler monkey (Carpenter, 1934; Glander, 1980) and the squirrel monkey (Travis \& Holmes, 1974; Coe \& Rosenblum, 1978), have been reported to have longer interbirth intervals and delayed fertility when nursing infants. However, members of the family Callitrichidae appear to be exceptions.

Callitrichids, marmosets and tamarins, are different from other primate families with respect to fertility and infant care. All group members participate in raising and carrying infants. Fecundity is high and twin births are most common. Post-partum to ovulation intervals, defined as the days between birth to the following ovulation, are short for the common marmoset (10-30 days: McNeilly et al., 1981; Dixson \& Lunn, 1987; Kholkute, 1987) and for the cotton-top tamarin (13-29 days: Ziegler et al., 1987a). When contrasting nursing and non-nursing females, interbirth intervals have not been statistically different for the common marmoset, the cotton-top tamarin or the saddle-back tamarin (Hampton \& Hampton, 1965; Wolfe et al., 1975; Phillips, 1976; Gengozian et al., 1978; Lunn \& McNeilly, 1982; French, 1983; Tardif et al., 1984). Only two reports have indicated that mean interbirth intervals are longer for nursing than non-nursing females in common marmosets, cotton-top tamarins, saddle-back tamarins and black-mantle tamarins (Wolfe et al., 1975; Lunn \& McNeilly, 1982). With all 4 species, however, the overlap in range of interbirth intervals between nursing and non-nursing animals was considerable although there appears to be a greater variability in interbirth interval range for nursing than non-nursing females. Hormonal data have been collected during the post-partum interval for the common marmoset, the cotton-top tamarin, the pygmy marmoset and the closely-related Goeldi's monkey. The hormonal data allow for a more precise estimate of post-partum fertility (McNeilly et al., 1981; Dixson \& Lunn, 1987; Ziegler et al., 1987a, 1989, 1990). McNeilly et al. (1981) reported a longer mean post-partum to ovulation interval in females nursing 2 infants than in females nursing 1 or 0 , but this difference was not significant. Mean time to conception, however, did differ significantly between the nursing and non-nursing mothers. Ziegler et al. (1987a) also found a tendency for the number of infants to affect the post-partum to ovulation interval. The mean post-partum to ovulation interval was longer in females that raised twins than in females that raised single infants or none. No effect of nursing on post-partum to ovulation intervals was found for the pygmy marmoset, although sample size was very small (Ziegler et al., 1990). The Goeldi's monkey also showed no reduction in fertility due to a nursing infant.

The objective of this study was to examine more closely the effects of nursing on the post-partum to ovulation interval in cotton-top tamarins. Both the number of infants nursed and differences in patterns of nursing behaviour across females were assessed.

\title{
Materials and Methods
}

\begin{abstract}
Animals. All females were captive born and living in the University of Wisconsin Tamarin Colony at the time of the study. The tamarins were all housed in families or as mated pairs in large complex cages. Details of housing and diet have been described by Snowdon et al. (1985). Urine samples were collected daily during the post-partum interval for 42 days or longer if conception had not occurred during this time. These data were collected from 12 females during 27 post-partum intervals from 1983 through 1989 and some of the hormonal data have been included in other reports (Ziegler et al., 1987a, b). The assumed day of the post-partum LH peak was estimated (184 $\pm 1 \cdot 14$, Ziegler et al., 1987a) for one of the 27 intervals by subtracting the gestational length from the interbirth interval since the female did not show any change in hormonal concentration for 42 days. First morning void urine was collected non-stressfully by holding a container directly under the female of interest after urination had begun. This method has been described fully by Ziegler et al. (1987a). Females were assigned to categories 0,1 or 2 by whether they did not nurse or nursed 1 or 2 infants post partum. When females did not nurse, it was due to parental neglect or neonatal death.
\end{abstract}


Hormonal assays. Urine samples were assayed for LH/CG and oestrone conjugates by RIA and for creatinine by spectrophotometric assay. The method for measuring $\mathrm{LH} / \mathrm{CG}$ was by a mixed heterologous LH RIA or a monkey CG RIA and the correlation between measures obtained with the two assays was high ( $r=0.98, n=33$ ). These methods both measure LH and CG and have been described by Ziegler et al. (1987a). Sensitivity of the LH RIA was $25 \mathrm{ng} / \mathrm{ml}$ in relation to a rhesus monkey LH reference preparation and sensitivity of the monkey CG RIA was $0.51 \mu 1$ of a rhesus monkey CG reference preparation. Intra- and interassay coefficients of variation for the LH RIA were $7 \cdot 1 \%$ and $8.5 \%(n=6)$ respectively and for monkey CG RIA were $4.3 \%$ and $9 \cdot 4 \%(n=8)$ respectively. Urinary oestrone conjugates were measured directly from the samples by the method described by Ziegler et al. (1987b). The sensitivity of the oestrone conjugates assay was $13 \mathrm{pg} /$ tube. Intra- and interassay coefficients of variation were $3.1 \%$ and $6.4 \%$ $(n=10)$ respectively. Creatinine was measured in each sample to compensate for variable fluid intake according to the method of Tietz (1976). Intra- and interassay coefficients of variation of the creatinine assay were $2 \cdot 1 \%$ and $5 \cdot 7 \%$, respectively. The hormonal profiles of the post-partum interval consisted of basal levels of urinary $\mathrm{LH} / \mathrm{CG}$ and oestrone conjugates that followed parturition until a 2-5-fold increase in LH/CG appeared and lasted 1-2 days. This LH peak was associated with increasing concentrations of oestrone conjugates that would remain elevated for approximately 12-16 days if conception did not occur or would continue to increase if conception and pregnancy followed. The LH peak occurring concurrently with rising oestrone conjugate values was assumed to be the approximate timing of ovulation and post-partum to ovulation interval lengths were defined as the days from parturition to the day of the highest elevation of the first post-partum LH peak.

Behavioural measurements. Behavioural data were collected from 7 mothers nursing twins during 10 lactations for 6 weeks. All behaviourally tested families were well habituated to the presence of the observer and had participated in other behavioural studies. Two types of instantaneous sampling were used to ensure that the data were not biased due to the presence of an observer. The first (15-min sessions) was intended for detailed information on nursing and consisted of two 15-min observation sessions twice a day, 3 days per week and were distributed so that morning, noon and afternoon observations were evenly represented. Every $30 \mathrm{sec}$ the name of the tamarin carrying the infant(s) and the position of the infant on the adult, i.e. back, axillary or other, were recorded. Infants carried by the mother were assumed to be nursing when they were in the axillary position. The second method (instantaneous scan) was intended to make frequent scans over the course of the day. This method allowed for immediate observation of the infants' position before reaction to the observer's presence could affect their behaviour. The name of the tamarin carrying the infant(s) was recorded 4 times per day: at wake-up $(\sim 08: 00 \mathrm{~h}), 10: 00 \mathrm{~h}, 12: 00 \mathrm{~h}$ and 14:00 h. Observations were divided into waking and daytime observations and waking was used as an index of night-time nursing. Contact was recorded for both methods as infant(s) on the mother in any position. Behavioural data are expressed as percentages of observations for individuals to account for unequal numbers of point samples among females.

Statistical analysis. Mean \pm standard error was used for all measures of the dispersal of the data. Two-tailed tests were used for all statistical analyses. The variance ratio test and Kruskal-Wallis nonparametric analysis of variance were used to examine any effects of the number of infants nursed on post-partum interval. Simple linear correlations were used to determine any relationships between parity or sex of infants and the post-partum to ovulation interval. Spearman's rank correlations were used to determine any relationships between number of care givers and infant contact, and between number of care givers, infant contact, or nursing behaviour and the post-partum to ovulation interval. The Wilcoxon paired-sample test was used to determine any differences in infant contact and nursing behaviour with I or 2 infants (see Zar, 1984, for statistical tests).

\section{Results}

Conception rate was determined for 25 of the 27 post-partum intervals. Two intervals were eliminated because one female had lost a mate during pregnancy and therefore could not become pregnant and one female was not monitored long enough after ovulation to determine whether conception had occurred. Of the 25 remaining intervals, $21(84 \%)$ resulted in conceptions.

Parity, sex of infants and number of infants nursed were analysed to determine any nonbehavioural influences on the length of the post-partum to ovulation interval. There was no significant correlation between parity of the female and the length of the post-partum to ovulation interval ( $r=0 \cdot 11, n=27$ ). The length of the post-partum to ovulation interval did not differ with the sex of the infants for females nursing twins with mean post-partum to ovulation intervals for male-male sets of twins being $26.7 \pm 4$ days $(n=3)$, for female-female sets of twins being $25 \cdot 5 \pm 1 \cdot 8$ days $(n=4)$, and for male-female sets of twins being $32 \cdot 1 \pm 2 \cdot 3$ days $(n=9)$ (KruskalWallis, $H=0 \cdot 24, P>0 \cdot 10$ ). No differences in post-partum to ovulation intervals were found when comparing the sex of twin infants born, whether the mothers had nursed or not, with mean intervals for male-male sets of twins being $26 \cdot 7 \pm 4$ days $(n=3)$, for female-female sets of twins being $23 \pm 1.6$ days $(n=5)$, and for male-female sets of twins being $27.9 \pm 1.5$ days $(n=12)$ (KruskalWallis, $H=2 \cdot 67, P>0 \cdot 10$ ). Sample size was too small for single infant sex comparisons. 
The length of the post-partum to ovulation interval differed significantly among females nursing none, 1 or 2 infants (Kruskal-Wallis, $H=6.27, P<0.05$ ). The mean length of postpartum to ovulation intervals was $16.5 \pm 1.6$ days for 6 non-nursing females, $16.5 \pm 3.7$ days for 4 females nursing 1 infant, and $30.8 \pm 5 \cdot 2$ days for 9 females nursing 2 infants (Fig. 1). Post-partum to ovulation lengths also differed significantly between non-nursing females bearing twins $(14.8 \pm 1 \cdot 6, n=4)$ and females bearing and nursing twins $(19 \cdot 4 \pm 4 \cdot 2, n=16)$ (Mann-Whitney Test, $U=53.5, P<0.05$ ). The length of the post-partum to ovulation interval varied within an individual female by a function of the number of infants nursed. Of the 12 females, 7 fell within more than one nursing category and nursed twins and 1 or 0 infants: 5 of the 7 females showed an increase in the length of the post-partum to ovulation interval with an increase in the number of nursing infants (Table 1). One female showed no difference between nursing 1 or 2 infants and one female had longer intervals when nursing 1 infant than 2 . The post-partum to ovulation interval was more variable in females that nursed infants when compared to non-nursing females (2-tailed variance ratio test, $P<0.01)$. The range of post-partum to ovulation intervals in 6 non-nursing females was $12-22$ days $\left(s^{2}=14 \cdot 7\right)$ and in 13 nursing females ( 1 or 2 infants) was $10-67$ days $\left(s^{2}=225 \cdot 3\right)$.

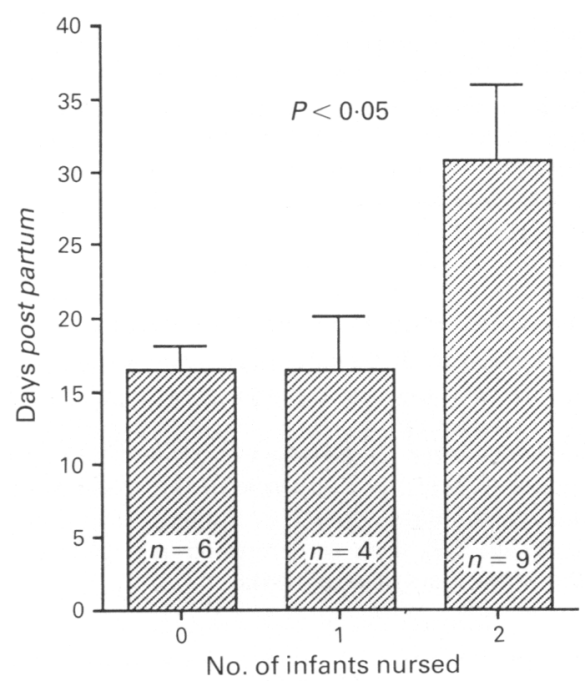

Fig. 1. The mean \pm s.e. days post partum as a function of the number of infants nursed by female cotton-top tamarins.

Table 1. Days to the LH peak from parturition in individual females by number of infants nursed

\begin{tabular}{lccc}
\hline & \multicolumn{3}{c}{ Number of infants nursed } \\
\cline { 2 - 4 } Female & 0 & 1 & 2 \\
\hline Rub & 22 & - & 29 \\
Mart & 15 & - & 26,30 \\
Gert & 13 & - & 34 \\
Mab & - & 14 & 27 \\
Hed & - & 10 & $39,47,67$ \\
Rox & - & 15 & 14 \\
Lind & - & 27 & 22,14 \\
\hline
\end{tabular}


Table 2 indicates the percentage of time mothers spent in contact with their infants. The two sampling methods compared well and both indicated that mothers spent less than $50 \%$ of total observation time in contact with their infants. The majority of maternal contact time was observed upon waking-up the family. In all conditions, mothers were observed to be in contact with 2 infants more than 1 . The number of care givers (number of other family members available to carry the infants, 1-9 family members) was negatively correlated with the percentage of time mothers carried their infants $\left(r_{\mathrm{s}}=-0.88, n=10, P<0.005\right)$. In other words, with a larger number of care givers, mothers spent less time in contact with their infants. However, neither the number of care givers in a family $\left(r_{\mathrm{s}}=0 \cdot 29, n=10, P>0 \cdot 30\right)$ nor the total amount of time the mother spent in contact with infants $\left(r_{\mathrm{s}}=0.433, n=10, P>0.10\right)$ correlated with the length of the post-partum to ovulation interval.

Table 2. The mean \pm s.e. percentage time 7 females nursing twins spent in contact with their infants

\begin{tabular}{lcccc}
\hline & 1 infant & 2 infants & All & 1 vs $2^{*}$ \\
\hline $\begin{array}{l}\text { I5-min sessions } \\
\text { \% Total observations }\end{array}$ & $12 \cdot 3 \pm 1 \cdot 7$ & $23 \cdot 3 \pm 6 \cdot 0$ & $35 \cdot 6 \pm 7 \cdot 1$ & $P<0 \cdot 10$ \\
$\begin{array}{l}\text { Instantaneous scan } \\
\text { \% Total observations }\end{array}$ & $17 \cdot 5 \pm 2 \cdot 3$ & $31 \cdot 5 \pm 5 \cdot 3$ & $49 \cdot 0 \pm 6 \cdot 7$ & $P<0 \cdot 01$ \\
\% Waking observations & $24 \cdot 4 \pm 2 \cdot 9$ & $63 \cdot 9 \pm 5 \cdot 7$ & $88 \cdot 3 \pm 4 \cdot 1$ & $P<0 \cdot 005$ \\
\% Daytime observations & $15 \cdot 4 \pm 3 \cdot 5$ & $20 \cdot 2 \pm 5 \cdot 4$ & $35 \cdot 6 \pm 8 \cdot 0$ & $P>0 \cdot 10$ \\
\hline
\end{tabular}

*Wilcoxon test for differences.

Data for nursing behaviour as obtained from 15-min sessions are found in Table 3 . Females were found nursing their infants less than $20 \%$ of the sampling time. However, when females were observed nursing their infants, they nursed them most often one at a time. There was a positive correlation between the percentage of nursing time that mothers nursed one infant and the length of the post-partum to ovulation interval $\left(r_{\mathrm{s}}=0.75, n=10, P<0.02\right.$; Fig. 2).

Table 3. The mean \pm s.e. percentage time 7 females spent nursing twin infants in 15-min sessions

\begin{tabular}{lcccc}
\hline & 1 infant & 2 infants & All & 1 vs $2^{*}$ \\
\hline$\%$ Total observation time & $10.3 \pm 1.5$ & $7 \cdot 4 \pm 1 \cdot 4$ & $17.7 \pm 2.4$ & $P>0.10$ \\
$\%$ Nursing time & $61.4 \pm 5.2$ & $38.7 \pm 5 \cdot 3$ & - & $P>0.10$ \\
\hline
\end{tabular}

*Wilcoxon test for differences.

\section{Discussion}

With post-partum conception rates as high as $84 \%$ and post-partum to ovulation intervals as short as 10 days while nursing, it is obvious that the cotton-top tamarin does not have a significant reduction of fertility due to lactation and nursing. However, the present data do indicate that the underlying mechanisms of suckling-induced delay of ovulation which have been observed in most other primates studied are also present in the cotton-top tamarin. The number of infants sucking and the frequency of nursing can delay the post-partum ovulation in the cotton-top tamarin.

Many primate species experience a refractory period post partum (McNeilly, 1988). At this time the hypothalamic-pituitary-ovarian axis is recovering from the suppressive effects of pregnancy. 


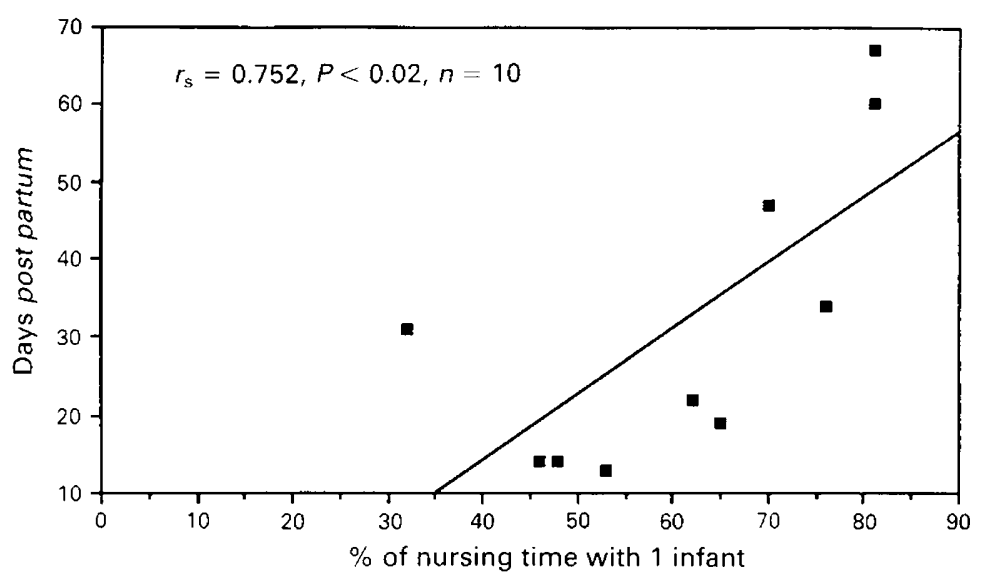

Fig. 2. The correlation (Spearman's) between the percentage time a female cotton-top tamarin nurses 1 infant at a time and the days post partum.

This delay in fertility is not due to lactation. The ovarian steroids are measured at basal concentrations as are pituitary $\mathrm{LH}$ and $\mathrm{FSH}$. In the cotton-top tamarin, measurement of urinary oestrone conjugates and $\mathrm{LH}$ have indicated that hormonal concentrations are also at basal values during this time. However, this refractory period may be short in the tamarin since an LH peak can occur as early as 10-14 days after parturition. In humans and macaques the refractory period in nonlactating females is generally followed by an inadequate ovarian cycle with insufficient formation of the corpus luteum and reduced progesterone excretion (McNeilly, 1988). In tamarins fertility appears to be complete with the first ovulation since the conception rate is $84 \%$ for the post-partum ovulation.

Since most primates usually bear only one infant at a birth, the number of infants nursed is not a factor in post-partum fertility reduction. In rodents which produce litters there is an effect of the number of infants nursing on the delay of oestrus (Rothchild, 1960; Van der Shoot et al., 1978). Pigs also have a longer post-partum to ovulation interval with increased litter size (Fahmy et al., 1979). An increased number of infants increases the intensity of suckling stimulus which in turn delays the onset of ovarian cycling. In the Goeldi's monkey which is closely related to tamarins and only produces a single infant, the post-partum to ovulation interval is a mean of $17 \cdot 8 \pm 6.3$ days and ovulation and conception do not appear to be delayed by nursing one infant (Ziegler et al., 1989). In our study it appeared that more than one tamarin infant needed to be nursed to cause a delay of the onset of cycling.

In most species of primates, only the mother carries her infant during the early weeks after birth. The infant has easy access to the nipple and an opportunity to nurse frequently. In humans who do not always carry their young there is a minimum nursing frequency that is required to maintain the fertility suppression. A study of breast-feeding females in Scotland and Denmark reported that ovulation never occurred when females nursed more than 5 times each day and a minimum nursing duration of 10 min per feed (Andersen \& Schioler, 1982; McNeilly et al., 1988). With US women, a suckling frequency of more than 6 times each day and a total duration of $80 \mathrm{~min}$ per day was required to suppress ovulation (Stern et al., 1986). In the !Kung society, women continue to nurse their infants at a high frequency and, therefore, continue the suppressive effects of nursing on ovulation for several years (Stern et al., 1986).

The social structure of callitrichid monkeys allows for less opportunity to nurse than is found with most other primates. From birth callitrichid infants are carried by many family members, thus reducing the amount of time the infants are in contact with their mothers. There is a positive correlation between increasing family size and decreasing contact time between mother and infants (McGrew, 1988; this paper). Even though an increase in mother's contact with her infants or 
increased family size does not correlate with increased post-partum to ovulation interval, the average amount of time a callitrichid mother spends with her infants is limited. In the present study, cotton-top tamarin infants were carried less than $50 \%$ of the day by their own mothers and therefore do not have the same opportunity to nurse that other primate infants have. Tamarin females were found nursing their infants less than $20 \%$ of the observation time. The low frequency of nursing seen in the cotton-top tamarin may be the reason that they do not have significant suppression of ovarian activity.

Absolute frequencies and durations of nursing bouts over the day could not be determined by the present observation techniques. However, 15-min sampling sessions indicated that nursing occurs at a low frequency. Infants that suck at infrequent intervals are limited in the amount of milk that can be consumed during a suckling bout (Oftedal, 1984). Infrequent nursing would therefore necessitate an increased energy and nutrient density of milk to allow longer intervals between nursing. Comparisons made on the milk composition of marmosets and tamarins with Old World monkeys and humans indicate a significantly higher protein content in the milk of marmosets and tamarins (Jenness \& Sloan, 1970; Buss, 1975; Turton et al., 1978). Therefore, marmosets and tamarins may not need to nurse their infants as frequently as do other primates.

An increased length of the post-partum to ovulation interval appeared to be due to increased nursing frequency by nursing one infant at a time. This strategy of nursing one infant at a time probably increased the total frequency of nursing and had the effect of increasing the length of the post-partum to ovulation interval. The nursing behaviour of individual females can affect their return to fertility.

We thank E. Kramer, W. Parsons and T. Dreyfus for help with sample collection; G. Scheffler, F. Wegner and D. Wittwer for technical assistance with hormone assays; and A. Savage for consultation on behavioural testing. This research was supported by grants $\mathrm{MH} 35,215$ and $\mathrm{MH} 00,177$ to C.T.S. and base grant RR 00167 to the Wisconsin Regional Primate Research Center.

\section{References}

Andersen, A.N. \& Schioler, V. (1982) Influence of breastfeeding pattern on pituitary-ovarian axis of women in an industrialized community. Am. J. Obstet. Gynec. 143, 673-677.

Buss, D.H. (1975) Composition of milk from a golden lion marmoset. Lab. Prim. New'sl. 14, 17-18.

Carpenter, C.R. (1934) A field study of the behaviour and social relations of howling monkeys. Comp. Psychol. Monogr. 10, 1-68.

Coe, C.L. \& Rosenblum, L.A. (1978) Annual reproductive strategy of the squirrel monkey (Saimiri sciureus). Folia Primatol. 29, 19-42.

Dixson, A.F. \& Lunn, S.F. (1987) Post-partum changes in hormones and sexual behaviour in captive groups of marmosets (Callithrix jacchus). Physiol. \& Behav. 41, $577-583$.

Fahmy, M.H., Holtman, W.B. \& Baker, R.D. (1979) Failure to recycle after weaning and weaning to oestrus interval in cross-bred sows. Anim. Prod. 29, 193-202.

French, J.A. (1983) Lactation and fertility: An examination of nursing and interbirth intervals in cotton-top tamarins (Saguinus o. oedipus). Folia Primatol. 40, $276-282$.

Gengozian, N., Batson, J.S. \& Smith, T.A. (1978) Breeding of marmosets in a colony environment. Prim. Med. 310, 71-78.

Glander, K.E. (1980) Reproduction and population growth in free-ranging mantled howling monkeys. Am. J. Phys. anthropol. 53, 25-36.

Hampton, J.K. \& Hampton, S.H. (1965) Marmosets (Hapiladae): Breeding seasons, twinning and sex of offspring. Science, NY 150, 915-917.

Jenness, R. \& Sloan, R.E. (1970) The composition of milks of various species: a review. Dairy Sci. Abstr. 32, 599-612.

Kholkute, S.D. (1987) Plasma estradiol and progesterone levels during postpartum ovulation and early pregnancy in the common marmoset Callithrix jacchus. Primates 25, 538-543.

Lunn, P.G. (1988) Malnutrition and fertility. In Natural Human Fertility. Social and Biological Determinants, pp. 135-152. Eds P. Diggory, M. Potts \& S. Teper. MacMillan Press, London.

Lunn, S.F. \& McNeilly, A.S. (1982) Failure of lactation to have a consistent effect on interbirth interval in the common marmoset. Callithrix jacchus jacchus. Folia Primatol. 37, 99-105.

McGrew, W.C. (1988) Parental division if infant caretaking varies with family composition in cotton-top tamarins. Anim. Behav. 36, 285-286.

McNeilly, A.S. (1988) Suckling and the control of gonadotropin secretion. In The Physiology of Reproduction, pp. 2323-2349. Eds E. Knobil \& J. Neill. Raven Press, New York.

McNeilly, A.S., Abbott, D.H., Lunn, S.F., Chambers, Downloaded from Bioscientifica.com at 04/26/2023 11:19:45AM via free access 
P.C. \& Hearn, J.P. (1981) Plasma prolactin concentrations during the ovarian cycle and lactation and their relationship to return of fertility post partum in the common marmoset (Callithrix jacchus). $J$. Reprod. Fert. 62, 353-360.

McNeilly, A.S., Howie, P.W. \& Glasier, A. (1988) Lactation and the return of ovulation. In Natural Human Fertility. Social and Biological Determinants, pp. 102-117. Eds P. Diggory, M. Potts \& S. Teper. MacMillan Press, London.

Nicolson, N.A. (1981) Suckling patterns, postpartum amenorrhea and birth intervals in wild baboons (Papio anubis). Ph.D. thesis, Harvard University.

Oftedal, O.T. (1984) Milk composition, milk yield and energy output at peak lactation: a comparative review. Symp. zool. Soc. Lond. 51, 33-85.

Phillips, I.R. (1976) The reproductive potential of the common cotton-eared marmoset (Callithrix jacchus) in captivity. J. med. Primatol. 5, 49-55.

Rothchild, 1. (1960) The corpus luteum-pituitary relationship in the rat. Endocrinology 67, 9-41.

Short, R.V. (1983) The biological basis for the contraceptive effects of breast-feeding. In Advances in International Maternal and Child Health, Vol. 3, pp. 325-343. Eds D. B. Jelliffe \& E. F. P. Jelliffe. Oxford University Press, Oxford.

Snowdon, C.T., Savage, A. \& McConnell, P.B. (1985) A breeding colony of cotton-top tamarins (Saguinus oedipus). Lab. Anim. Sci. 35, 477-480.

Stern, J.M., Konner, M., Herman, T.N. \& Reichlin, S. (1986) Nursing behaviour, prolactin and post-partum amenorrhoea during prolonged lactation in American and !Kung mothers. Clin. Endocrinol. 25, 247-258.

Stewart, K.J. (1988) Suckling and lactational anoestrus in wild gorillas (Gorilla gorilla). J. Reprod. Fert. 83, 627-634.

Tardif, S.D., Richter, C.B. \& Carson, R.L. (1984) Reproductive performance of three species of Callitrichidae. Lab. Anim. Sci. 84, 272-275.

Tietz, N.W. (1976) Fundamentals of Clinical Chemistry. W.B. Saunders, Philadelphia.

Travis, J.C. \& Holmes, W.N. (1974) Some physiological and behavioural changes associated with oestrus and pregnancy in the squirrel monkey (Saimiri scuireus). J. Zool. Lond. 174, 41-66.

Turton, J.A., Ford, D.J., Bleby, J., Hall, B.M. \& Whiting, R. (1978) Composition of the milk of the common marmoset (Callithrix jacchus) and milk substitutes used in hand-rearing programmes, with special reference to fatty acids. Folia Primatol. 29, 64-79.

Tutin, C.E.G. (1980) Reproductive behaviour of wild chimpanzees in the Gombe National Park, Tanzania. J. Reprod. Fert., Suppl. 28, 43-57.

Van der Shoot, P., Lankhorst, R.R., de Roo, J.A. \& de Greef, W.J. (1978) Suckling stimulus, lactation and suppression of ovulation in the rat. Endocrinology 103, 949-956.

Wolf, R.H., Harrison, R.M. \& Martin, T.W. (1975) A review of reproductive patterns in New World monkeys. Lab. Anim. Sci. 25, 814-821.

Wolfe, L.G., Deinhardt, F., Ogden, J.D., Adams, M.R. \& Fisher, L.E. (1975) Reproduction of wild-caught and laboratory-born marmoset species used in biomedical research (Saguinus sp, Callithrix jacchus), Lab. Anim. Sci. 25, 802-813.

Zar, J.H. (1984) Biostatistical Analysis, 2nd edn. PrenticeHall, Englewood Cliffs.

Ziegler, T.E., Bridson, W.E., Snowdon, C.T. \& Eman, S. (1987a) Urinary gonadotropin and estrogen excretion during the postpartum estrus, conception, and pregnancy in the cotton-top tamarin (Saguinus oedipus oedipus). Am. J. Primatol. 12, 127-140.

Ziegler, T.E., Savage, A., Scheffler, G. \& Snowdon, C.T. (1987b) The endocrinology of puberty and reproductive functioning in female cotton-top tamarins (Saguinus oedipus) under varying social conditions. Biol. Reprod. 37, 618-627.

Ziegler, T.E., Snowdon, C.T. \& Warneke, M. (1989) Postpartum ovulation and conception in Goeldi's monkey, Callimico goeldii. Folia Primatol. 52, 206-210.

Ziegler, T.E., Snowdon, C.T. \& Bridson, W.E. (1990) Reproductive performance and excretion of urinary estrogens and gonadotropins in the female pygmy marmoset (Cebuella pygmaea). Am. J. Primatol.

Received 20 March 1990 